\title{
DEVELOPMENT OF PRODUCTS STATE IDENTIFICATION APPLICATION
}

\author{
Stefan Đurđević (iD, Dragoljub Novaković (iD), Željko Zeljković (iD) \\ University of Novi Sad, Faculty of Technical Sciences, \\ Department of graphic engineering and design, Novi Sad, Serbia
}

\begin{abstract}
The subject of this paper is the development and design solution of an application for product identification with smart packaging. The main goal of the study is to examine the functionality of a relatively new application design program "Adobe XD" company - "Adobe" as well as creating an application that will allow each user to very easily navigate through it. The main goal of the application is to give the user more information about the product than the packaging itself and help him choose the right product. The development of the application was preceded by research in the field of smart packaging and product state identification. This paper aims to set up an intuitive system in the form of a mobile application that would identify the product state and the information would be unambiguously obtained on the mobile device screen.
\end{abstract}

Key words: smart packaging, application design, user experience design, products state

\section{INTRODUCTION}

The term smart packaging is used for packaging that, in addition to its essential functions, also has other specific characteristics. Smart packaging systems are used in several branches of the economy, primarily in the food and pharmaceutical industries, in order to facilitate the use of the product, preserve its quality, as well as provide information about the current state of the product (Figure 1) (Obradović, 2000).
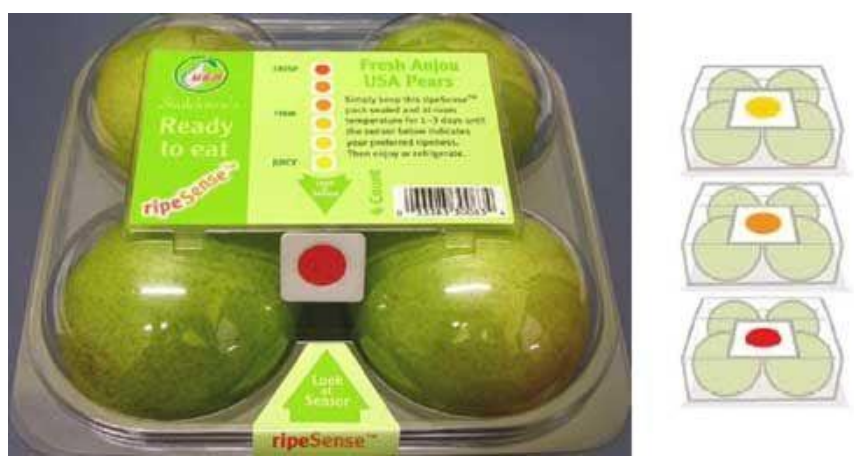

Figure 1: Product state estimation using smart packaging

Intelligent packaging is characterized by the fact that it allows the consumer to monitor information about the production of the product directly. The packaging and consumer interaction is enabled through indicators and sensors that are built into the packaging itself (Miočić, 2015).

\section{METHODS}

For creating design and interaction through an application, the program "Adobe XD 2019" was used in combination with programs such as "Adobe Photoshop 2017" and "Adobe Illustrator 2017" (Adobe, 2020).

The idea is to create an application that will enable the end-user (buyer) easier and simpler shopping during the buying process. Scanning the smart packaging will provide more information about the product compared to the basic information that can be found on the conventional packaging. After scanning the product, the application will load a specific site with a complete product description, such as - name, price, product rating, product stock information, information on intolerance to certain additives such as gluten, lactose, soy, carrageenan, etc.). Also there are comments and previous experiences of users who have already tried the product. Basic information about the product and its specifics, product 
ingredients, instructions for use, date of manufacture or expiration date of the product, net quantity and freshness of the product are also included.

Application creation is based on the basic algorithm that contains four main sections: 1 . Printed codes (Barcode, QR code) 2. Printed electronics and sensors - (RFID, NFC, Beacon, Sensor) 3. Smart indicators (TTI, Freshness, Gas indicators, Chromatic indicators); 4. Augmented Reality (Figure 2) (Đurđević, 2020).

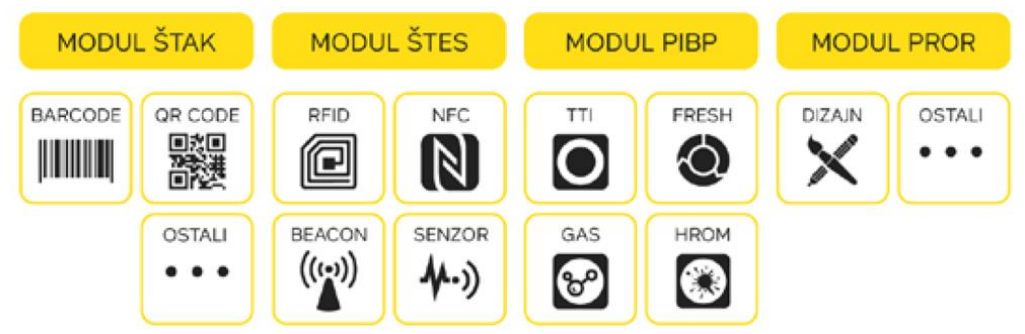

Figure 2: Algorithm as a guide for application development

\section{RESULTS}

After starting, the application is designed to load the home page and start the reading. As this application is used exclusively for scanning products, it is necessary to press the "scan" button, which takes us to page with four types of scanning. Based on the four main types of smart packaging given in algorithm, there are four different types of scans. Figure 3 shows the steps to reach the scanning page.

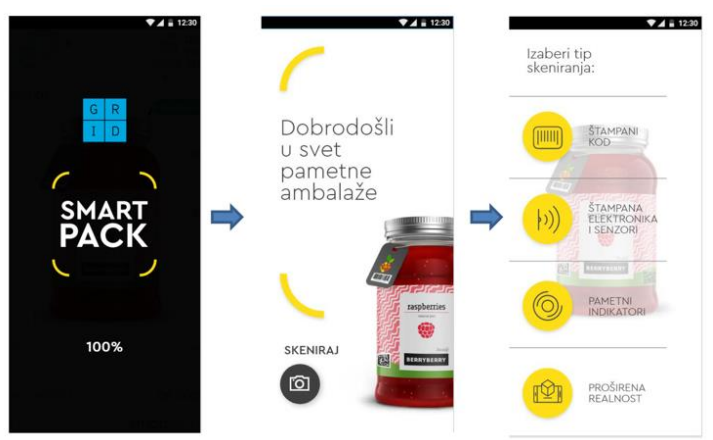

Figure 3: Initial application screens

The first button or the first type of scan is the printed code. The printed code consists of two types of codes, Bar code and QR code. When this button is pressed, the page is loaded, and we get a division where we can choose which type of scan we want. After selecting, the camera on the phone automatically starts where a predefined, transparent "frame" is placed over it, which narrows the range of the camera to one smaller square. It is necessary to find a barcode or QR code on the product and centre it in that box in order for the application to detect and scan it. When the camera finds the specific code, the application offers to "take a picture" option located at the bottom of the screen (Figure 4).
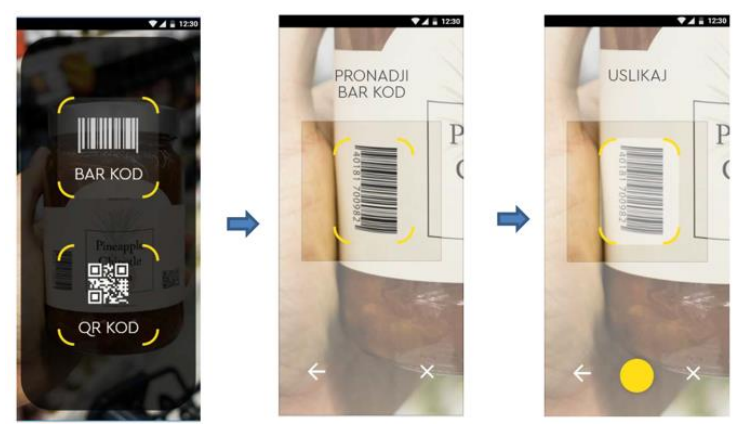

Figure 4: Code selection and scanning 
The second type of scanning is related to printed electronics and sensors. By selecting this type, four buttons appear - 2 buttons for printed electronics and two buttons for sensors. By pressing the button, a short explanation appears to the user on how to place the phone in front of the product (packaging). The distance between the phone and the indicator on the packaging must not exceed 10 centimetres in order for the application to detect it and link to the given site related to the product (Figure 5).
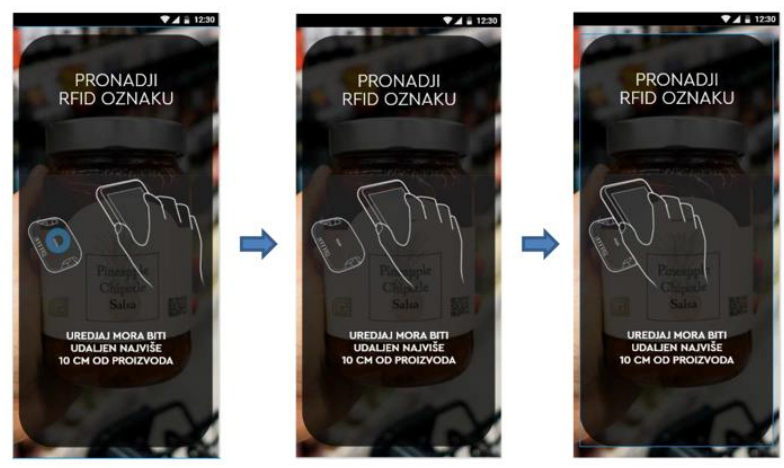

Figure 5: Finding correct distance between the phone and the indicator

A few seconds after this explanation (Figure 5), when the required indicator is found (in this case RFID or NFC indicators), the application automatically opens the product page with a "pop up" window with basic product information (unlike codes where it is necessary to take pictures of the code). By clicking on the "link" button or "pop up" window - the application sends us to the address of the main page about the product.

The next example in the application are beacons, and if we select this module, the application automatically launches the "Google Map" application, with blurred map because the emphasis is placed on the notification related to the product. In order for the application to recognize immediate vicinity, the smartphone location services must be turned on. Two buttons appear on the screen - the first "see product" button sends the user to the main page so that the user can decide if he wants to view it. The second "show path" button actually plots the path from the user to the store where the product is located inside store.

Smart indicators are the third type of devices placed on the packaging and ready to scan. The scanning principle is similar to indicator scanning. The application detects the indicator and offers the option to go to the main site with product details. Unlike the first three types, which are detected by indicators, the condition is detected on the packaging using smart (colour-changing chromatic) ink.

The fourth type is perhaps the most exciting in the visual sense because it uses augmented reality technology. Video and audio effects give the customer a superior feeling to which a particular product is experienced in real-time (Figure 6). These effects can be entertaining but also informative. When it comes to effects of an entertaining nature, these are usually effects that create a more complete and more precise image of the product, while informative effects are most often some novelties added to the product or some actions that are related to the product at that time. When the augmented reality button is pressed, after reading, the camera on the phone automatically turns on.

On the screen, the user can see the request to scan the product. When the product is brought to a required position, the application scans the packaging (product) by starting to draw an "outline" line and detecting it. A few seconds after scanning, two new buttons appear on the screen: "Run $A R^{\prime \prime}$ and the "About Product" button.

If the "Run AR" button is selected, video and audio effects will be displayed along with the scanned product in real-time. If the "About product" button is selected, the application takes the user to the main page with detailed product information. 


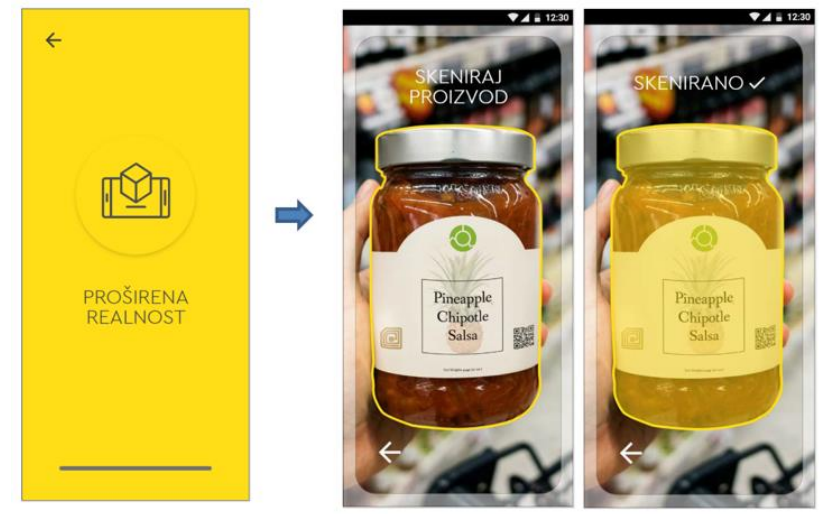

Figure 6: Product scanning via Augmented Reality module

We can conclude that each of these scanning types leads us to the main page, which is the target destination and which contains all the information related to a given product. This page is longer than the size of a single screen, so a "slider" has been added to make it easier to navigate through the app, making it easier to interact.

The first and most important information for most users is at the very beginning of the page and is related to the product price, product evaluation (users comments about the product), the option for the user to evaluate the product, product stock information and information on whether the product contains any additions the potential buyer is intolerant (Figure 7).
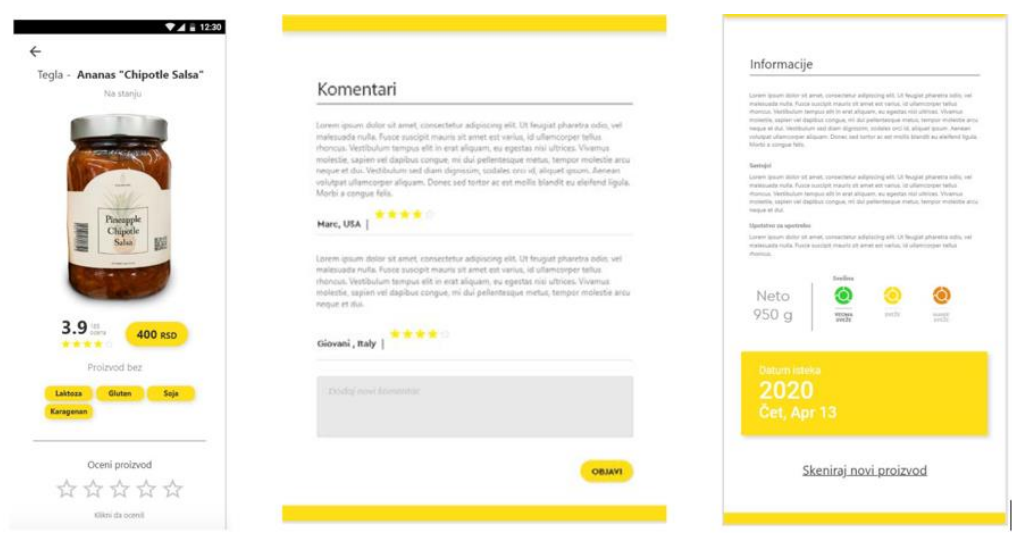

Figure 7. More detailed product information, comments and other information

There is also a section with comments from previous users and their experiences with that product. It is also possible to leave a comment here, just username and country name will be printed with the posted comment. When the comment is sent, by clicking on the "publish" button, it will be automatically added to the site.

The section below the comments is related to the information from the product declaration. Here user can find information such as the manufacturer name, country of origin, distributor, ingredients, allergens, instructions for use, product freshness, net weight as well as the product expiration date. All this information is static (does not change), except for the freshness information, which is directly related to the smart packaging and changes over time depending on the product freshness.

At the end of the page, there is an option or button "scan new product" that returns the interface to the first page in case user want to scan a new product to compare with the current one.

\section{CONCLUSIONS}

Based on the market demand, there is a growing need of the user, in this case, the customer, for technologies that more easily and quickly lead the customer to the desired product or service. In addition to these benefits, the customer becomes dissatisfied with the necessary information we can find on the 
product, and thus smart packaging becomes a precedent in choosing the desired product. In combination with the newly created application, more detailed and extensive information is offered. As a new program by Adobe, Adobe XD is becoming a revolutionary "User Experience" program with advanced interaction with the UI designer, which facilitates the development of applications necessary for the "revival" of smart indicators on the packaging.

\section{ACKNOWLEDGMENTS}

This research(paper) has been supported by the Ministry of Education, Science and Technological Development through the project no. 451-03-68/2020-14/200156: "Innovative scientific and artistic research from the FTS (activity) domain".

\section{REFERENCES}

[1] Adobe: "Creative Cloud", URL: https://www.adobe.com/creativecloud.html (last request: 2020-07-20).

[2] Đurđević, S.: "Model identifikacije stanja zaštitnih elemenata grafičke ambalaže", PhD thesis, University of Novi Sad, Faculty of Technical Sciences, 2020.

[3] Miočić, L.: "Osiguravanje kvalitete u procesu razvoja inovativne ambalaže", BSc thesis, University of Zagreb, 2015.

[4] Obradović, T.: "Savremena izrada ambalaže", (Data status, Beograd, 2000.)

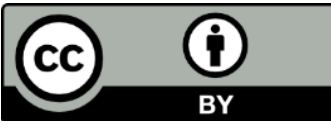

(C) 2020 Authors. Published by the University of Novi Sad, Faculty of Technical Sciences, Department of Graphic Engineering and Design. This article is an open access article distributed under the terms and conditions of the Creative Commons Attribution license 3.0 Serbia (http://creativecommons.org/licenses/by/3.0/rs/). 